RESEARCH ARTICLE

\title{
Cedar Project: Conducting Health Research with Indigenous Peoples in a Good Way
}

\author{
For the Cedar Project Partnership \\ Richa Sharma \\ School of Population and Public Health, University of British Columbia
}

Violet Bozoki

Elder - Lheidli T'enneh, British Columbia

Earl Henderson

Elder - Cree, Métis, British Columbia

Lou Demerais

Elder - Cree, Métis, British Columbia

Kukpi7 Wayne Christian

Splats'in First Nation, British Columbia

Sherri Pooyak

Canadian Aboriginal AIDS Network, Saskatchewan

Vicky Thomas

Cedar Project, British Columbia

Margo Pearce

School of Population and Public Health, University of British Columbia

Kate Jongbloed

School of Population and Public Health, University of British Columbia

April Mazzuca

School of Population and Public Health, University of British Columbia

Patricia Spittal

BC Children's Hospital Research Institute

The Cedar Project is an interdisciplinary, community-driven research project responding to the crises of HIV and Hepatitis C infection and contributing to the healing of young Indigenous people who use or have used drugs. We are a collective membership of Indigenous Elders, health/social service experts, researchers, and non-Indigenous allies. We situate our work in the context of strength, resilience, and rights to selfdetermination for Indigenous peoples while also acknowledging the ongoing impacts of historical, intergenerational, and current trauma, specifically those related to the child welfare systems. We provide epidemiological and qualitative evidence that reflects Indigenous perspectives of health and wellness. In this paper, we highlight over seventeen years of shared learnings on conducting research with Indigenous communities in a good way. Specifically, we elaborate on four key components of 
our unique project. First, our paradigm is to build on young Indigenous people's strengths while acknowledging grief and historical trauma. We recognize that Cedar participants are not statistics_they are relatives of Indigenous partners governing this study. Second, our processes are determined by Indigenous governance, led by Elders and rooted in cultural safety. Third, our research ethics are determined by terms of reference created by the Cedar Project Partnership and by embracing guidelines of TCPS and community-based research. Fourth, we are informed by multiple perspectives and research relationships between Elders, partners, students, academics, and research staff. Sharing our learnings with the larger research community can contribute to decolonizing research spaces by centering Indigenous knowledges and privileging Indigenous voice.

Keywords: Indigenous research; community-based health research; Indigenous ethics

\section{Introduction}

"In a good way" is a teaching shared by Elder Earl Henderson (Cree, Métis). It refers to incorporating traditional teachings in our lives and carrying ourselves with honesty, humility, truth, love, compassion, respect, honour, and forgiveness.

Cedar Project (Cedar) is an interdisciplinary research project responding to the crises of HIV and Hepatitis $\mathrm{C}(\mathrm{HCV})$ infection and contributing to health and healing among young Indigenous people who use or have used drugs. We are a community-driven cohort involving eight hundred participants in Vancouver and Prince George, on the traditional territories of the Coast Salish and Lheidli T'enneh peoples. We recognize the strength, resilience, and rights to self-determination of Indigenous peoples since time immemorial (recognized by British Columbia law in 2019 with Bill 41 - Declaration on the Rights of Indigenous Peoples Act, s.2 and s.3) while acknowledging the ongoing impacts of historical and intergenerational trauma. Since inception in 2003, we have received continuous funding from the Canadian Institute of Health Research (CIHR).

At Cedar's initiation, which pre-dates the Truth and Reconciliation Commission (TRC), we recognized that the creation of a culturally safe research process, governed by an Indigenous advisory group, was necessary to ensure that the work was impactful and relevant to communities. Approached in this way, research can be empowering, healing, and self-determining. Indigenous Elders and leaders, collectively known as the Cedar Project Partnership, have governed the research process. This long-standing and dynamic partnership is situated within an Indigenous-led governance model that provides protection, leadership, and support and that ensures self-determining ethical principles and Indigenous knowledges are upheld and respected. The Partnership is a governance body presiding over the study. It includes three Elders-Violet Bozoki (Lheidli T'enneh), Earl Henderson (Cree, Métis), and Lou Demerais (Cree, Métis)-and leadership from Carrier Sekani Family Services (CSFS); Positive Living North (PLN); Central Interior Native Health Society (CINHS); Prince George Native Friendship Centre (PGNFC); Splats'in Secwepemc Nation; Canadian Aboriginal AIDS Network (CAAN); Vancouver Native Health Society (VNHS); All Nations Hope (ANH); and Katharina Patterson (Nil Tu,O on Vancouver Island). Previous members also included Healing Our Spirit and the HIV Red Road Network, organizations that are now closed due to lack of HIV research funding. The researchers provide epidemiological and qualitative evidence that reflects Indigenous perspectives of health and wellness and is used by Cedar partners for advocating for the young people in their communities and Nations. This study has contributed to dialogue, service provisions, policy, education, and research standards related to Indigenous health in British Columbia.

In this paper, we highlight over seventeen years of shared learnings on conducting research with Indigenous communities in a good way. Specifically, we elaborate on four key components of our unique project. First, our paradigm is to build on young Indigenous people's strengths while acknowledging grief and historical trauma. Our research with urban young Indigenous people on resilience, HIV- and HCV-related vulnerabilities, and experiences with structural risks such as systemic racism and over-policing is situated within the context of the ongoing impacts of colonial genocide. Second, our processes are determined by Indigenous governance (the Cedar Project Partnership, led by Elders) and rooted in cultural safety, extensive knowledge translation, and community engagement. We reflect on how Indigenous governance is a key aspect of our research practice and its impact on our methodologies. Third, our research ethics are determined by the terms of reference set out by our governance body (the Cedar Project Partnership), by embracing the guidelines of the Tri-Council Policy Statement: Ethical Conduct for Research Involving Humans (TCPS), Chapter 9, and through community-based research. We discuss the importance of Indigenous 
oversight over the research process in academic institutions designed to undermine Indigenous authority. Finally, we are informed by multiple perspectives and research relationships between Elders, partners, students, academics, and research staff, but Indigenous voice is privileged. These perspectives are woven throughout the paper to illustrate critical aspects of our paradigm and processes.

\section{Paradigm}

This whole process is about worldview. What we are doing is, we have two worldviews - Indigenous and Euro-centric-walking alongside each other, not dominating one another. This process has really brought out-the numbers are not numbers, they are our relations. It's the human context, that's what happened over the fifteen years, worldview has intersected with the academic world. Bringing that worldview to light, and helping open up that dialogue, you can call it reconciliation, but ideally building that foundation is how we need to move forward. Think of all the students associated with Cedar, how we changed their mindsets, and their paradigms, so they are not just talking about the medicine, it's all about relationships. People don't develop those relationships with us on equal footing. It's enough of that. That's what this partnership is about. (Kukpi7 Wayne Christian, Secwepemc Nation, Partnership member, Co-PI, Cedar Partnership 2018a)

\section{History and Research Lens}

Cedar governance was established to oversee community-driven research on the disproportionate impacts of HIV/AIDS and HCV epidemics among Indigenous people in British Columbia. In 2003, Indigenous leaders in Vancouver and Prince George, British Columbia, invited researchers to address historical and ongoing impacts of settler colonial trauma that young Indigenous people were experiencing. At the time, questions arose as to whether there was a simmering epidemic of HIV among young Indigenous people in the North. HIV/AIDS service organizations in Prince George were concerned about the disproportionate number of Indigenous clients at the needle exchange, inadequate access to injection equipment on reserve, the overrepresentation of young Indigenous women in survival sex work, and violence against Indigenous women, as evidenced by the Highway of Tears and the Pickton farm killings (Oppal 2012). Despite research emerging from Vancouver at the time, few studies offered perspectives on the experiences and challenges of young Indigenous people who faced immense structural risks, including HIV-related vulnerability, over-policing, and systemic racism, in Northern British Columbia (Fournier and Crey 1997; Craib et al. 2003; Capostinsky 2007). The researchers were directed to provide a critical evidence base for what Indigenous peoples already knew. This project was designed to provide Indigenous leaders and investigators with the epidemiological evidence necessary to lobby on behalf of their communities and Nations for increased prevention/care resources. Our governance model was established prior to responding to CIHR calls for funding.

Under the direction of the Cedar Project Partnership, we adopted the research lens that young Indigenous people use drugs as stress-coping because they are in pain, and HIV-related vulnerability must begin with a consideration of the historical legacy of colonization, including forced removal from traditional lands, cultural genocide, and the history of the residential school system and the child welfare system (Walter and Simoni 2002; For the Cedar Project Partnership 2008). For over a century, the central goals of Canada's Indigenous policy have been to eliminate Indigenous governments; ignore Indigenous rights; terminate the Treaties; and, through a process of assimilation, cause Indigenous peoples to cease to exist as distinct legal, social, cultural, religious, and racial entities in Canada (Institute on Governance 1997; Truth and Reconciliation Commission of Canada 2015).

Cedar participants have navigated the strangling impacts of these oppressive systems throughout their lives. At inception, Cedar governance tasked the researchers to address the impacts of sexual abuse and foster care. They instructed the researchers to include questions on residential schools, separation from biological parents, and childhood sexual abuse in our questionnaires. Under their leadership, Cedar was able to provide staggering results. We found that nearly half of our participants reported sexual abuse that was associated with having a parent who attended residential school, foster care, or HIV infection (For the Cedar Project Partnership 2008). Chief Christian (Secwepemc Nation), co-principal investigator of Cedar, describes this process:

As a governing partnership, we directed the researchers to look at prevalence of sexual abuse among our young people, as well as relationships between residential schools and the current child welfare system-that we already knew, but the research made that academic connection. One of the most troubling findings for me, as a father and grandfather, is that the average age of first experience of sexual abuse was six years old. Some children are being hurt in this way before they can even speak. I myself am a survivor of the foster care system and of sexual abuse. I know the pain of these young people. We took this data and are using it to advocate for our young people. (Christian 2013) 
Another early study from Cedar (Craib et al. 2009) examined the impact of HCV on young Indigenous people who use drugs. We found an alarmingly high prevalence of HCV, and due to the foresight of our Elders and the Partnership, we were the first study, to our knowledge, to reveal a statistical connection between residential schooling of parents and the rates of $\mathrm{HCV}$ in their children. Over time, our findings continued to affirm what Indigenous communities already knew-that intergenerational trauma exacerbates risk for HIV, illness, and death (Christian and Spittal 2008). Cedar research has affirmed that young Indigenous people who use(d) drugs are disproportionately impacted by HIV/AIDS, HCV, survival sex work, sexual assault, and ongoing violence and discrimination from the Canadian state, especially the current child welfare system, which impacts their self-determination and resilience (Spittal et al. 2007; For the Cedar Project Partnership 2008; Mehrabadi et al. 2008; Moniruzzaman et al. 2009; Spittal et al. 2012; Pan et al. 2013; For the Cedar Project Partnership 2015; Pearce et al. 2015a; Pearce et al. 2015b). Recently, we released findings demonstrating that young Indigenous people who use drugs in British Columbia are dying at a rate nearly thirteen times Canadians their age, and we identified concerning associations between death and HCV, having previously attempted suicide, and recent non-fatal overdose (Jongbloed et al. 2017).

As these sobering results started to emerge in the early years, Cedar governance then directed the researchers to shift discourse from the stress-coping paradigm towards strengths-based research affirming links between health and wellness, cultural connection, and resilience (Tousignant and Sioui 2009; Chandler and Lalonde 1998). As Mary Teegee (Gitk'san and Carrier, Takla Lake), a Cedar Project partner from Carrier Sekani Family Services explained, "We directed the scientists to look at the traumas, but also the resilience, because we are here, we exist, even after 500 years of colonization" (Caron et al. 2016). Cedar Project partner Sherri Pooyak (Cree), Community-Based Research Manager at the Aboriginal HIV/AIDS Community-Based Research Collaborative Centre (AHA Centre), further explained the importance of researching sources of strength, resilience, and connection to Indigenous cultures:

So much of what is written about Indigenous people comes from a very deficit model ... you read anything about us, and we're always the "highest" whether that's HIV, HCV, diabetes, arthritis, or cancer. It's really important for me that we look at all the other strengths, especially with our participants. We really need to focus on these strengths, the way participants have been able to survive themselves. (Cedar Project Partnership 2018b)

In 2011, study Elders developed questions related to cultural connection, including language, ceremony, and traditional foods. Cedar Project Coordinator Vicky Thomas (Wuikinuxv Nation) describes the impact of asking strengths-based questions from an Indigenous perspective:

Having the cultural questions allows us to look at resilience and strength not just in a Western way, but in an Indigenous way. We know that our wellness and social determinants of health come from our identities, our families, our cultures, our languages, and our land. So, having these questions is just as-if not more-important than asking about resilience from a more Western perspective. (Cedar Project Partnership 2018b)

These questions, combined with a resilience questionnaire, were used to statistically demonstrate what Indigenous people have known for centuries: speaking traditional languages and participating in ceremonies is associated with higher resilience, regardless of abuse experiences (Pearce et al. 2015a). This approach aligns with the Indigenous worldview, as highlighted by the First Nations Health Authority (FNHA), that focusing on strengths-based indicators and wellness can lead to improved healthcare and health outcomes for Indigenous peoples (First Nations Health Authority 2014). Subsequently, this landmark paper was integrated into curricula at British Columbia universities to facilitate decolonizing learning for trainee health professionals/researchers to move beyond a deficit-based understanding of Indigenous health.

\section{Terms of Reference}

Underpinning this work are the terms of reference established by the Cedar Project Partnership. As Cedar participants represent many of the diverse Indigenous communities and Nations across British Columbia and Canada, the cedar tree-the tree of life-was identified as a powerful metaphor for healing and wellness because it looks at a person's wholistic way of being. The Cedar Project Partnership Terms of Reference were built on this metaphor of the cedar tree and include four key components: the roots, the trunk, the branches, and the foliage. This project is based on sincere and transparent communication between the Cedar Project Partnership members and researchers. Researchers must abide by the Cedar Project 


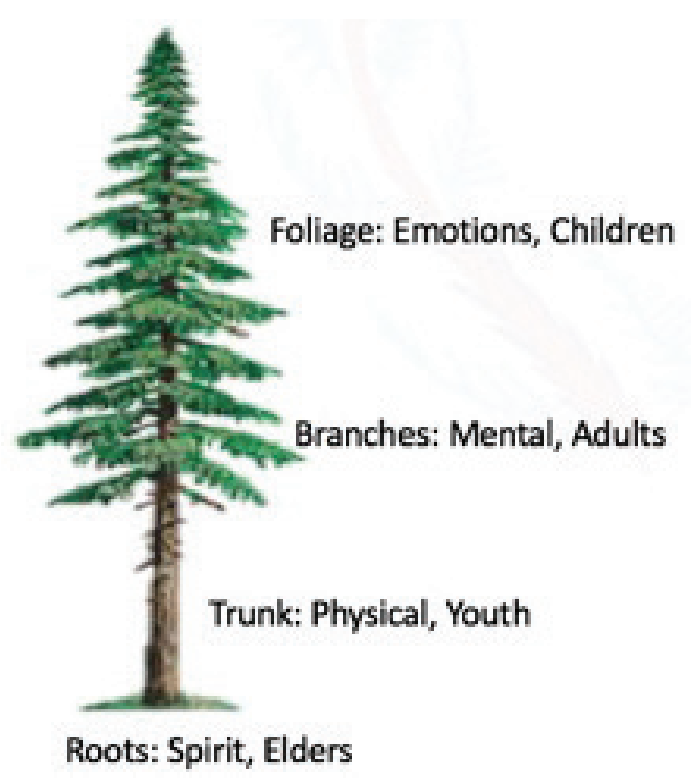

Figure 1: Cedar Project Terms of Reference. Image reproduced with permission of Cedar Project Partnership.

Terms of Reference (Figure 1) in all phases of the research, as part of their commitment to reciprocal accountability.

Roots (Spirit, Elders): The roots are the oldest part of the tree, and they signify the Elders guiding the Cedar Project. The roots hold the knowledge and provide nourishment to the rest of the tree. The Elders are the knowledge keepers and provide guidance and wisdom to the rest of the community. Cedar governance uses the guiding principles of Elders, ancestors, and traditional teachings when we meet. The spirit of Indigenous peoples is the core of what guides the Partnership in the decisions that are made. Although we have many different Nations represented in our governance, there are common themes that have been handed down from our Elders-the Partnership ensures that these teachings are listened to and used in this work. These include truth, honesty, humility, discipline, love, honour, respect, patience, thankfulness, obedience, happiness, and hope. Elders' teachings and guidance are incorporated throughout the research process, from developing new research questions to communicating findings back to the community and the general public. For example, all Partnership meetings start and end with prayer. Everyone is encouraged to pray in their own language, and smudge is offered for those interested the beginning of each meeting. Partnership meetings always include Elders - they are the carriers of history and knowledge, and they bring wisdom and teachings that need to be followed. Elders are our strength and we ask for their guidance when making any decisions.

Trunk (Physical, Youth): The trunk represents the young people, the core focus of this project, anchored by the roots/Elders and surrounded by branches/adults. The physical aspect represents the strength and ability of the young people. The Cedar Project Partnership is a community standing together, protecting and guiding one another. This collective is cognizant that the work is being done with young people who are speaking about their pain. We prioritize listening to the voices and stories of young Indigenous people.

Branches (Mental, Adults): The adults are the branches, surrounding the trunk/youth. The mental aspect represents the adults' responsibility to protect and shield the youth and the children by creating a positive environment for them. As adults and leaders of their communities, we have the responsibility of ensuring that the voices of our most vulnerable community members are heard. We have a responsibility to ensure that our communities are no longer being colonized. Systems such as healthcare, child welfare, education, the justice system, and housing should meet the needs of young Indigenous people and the community as whole, and these systems must treat Indigenous communities with dignity and respect. We are committed to providing epidemiological evidence to show how settler colonial systems create risk for young Indigenous people through the impacts of intergenerational trauma, while also centering their resilience. The Partnership uses this evidence to advocate for the young people in their communities. 
Foliage (Emotions, Children): The children represent the little buds on the branches, filled with life and emotions. All aspects of the tree are responsible for nurturing and nourishing the foliage. This research project, guided by the Elders, is conducted by Indigenous leaders and community members to support their young people, with the vision of a healthier community and future for Indigenous children.

\section{Process}

The Cedar Project Partnership is led by Elders; provides governance, leadership, and support for the study; and makes sure that the collective follows decolonizing principles of Indigenous research standards. This includes centering Indigenous knowledges and epistemologies while working within the parameters of a Western academic institution, approaching research as ceremony, establishing relational accountability to ensure that the work is done in service for Indigenous communities, and leaning into Indigenous methodologies such as storytelling and sharing circles in tandem with epidemiological methods (Smith 1999; Wilson 2008; Kovach 2009).

The Partnership surrounds the study (Figure 2). Cedar Project governance upholds the voices of young Indigenous people by surrounding them in a circle of care. Participants are supported by research staff who conduct the study and have long-standing relationships with them. As Elder Violet Bozoki (Lheidli T'enneh) describes, "They are the ones going through the grief with the participants. They know their story. They love them" (Violet Bozoki, personal communication to Richa Sharma and Vicky Thomas, June 23, 2020). Cedar staff are surrounded by the Partnership, who lead the study to make sure that the work is done in a good way, including oversight of the researchers and data management, which is all based at BC Children's Hospital Research Institute in Vancouver. As Cedar Project Coordinator Vicky Thomas (Wuikinuxv Nation) describes, "The Partnership wraps us in their care and love to make sure that we can do this work in a good way. They are there to hold us true to Indigenous accountability" (Cedar Project Partnership 2018b).

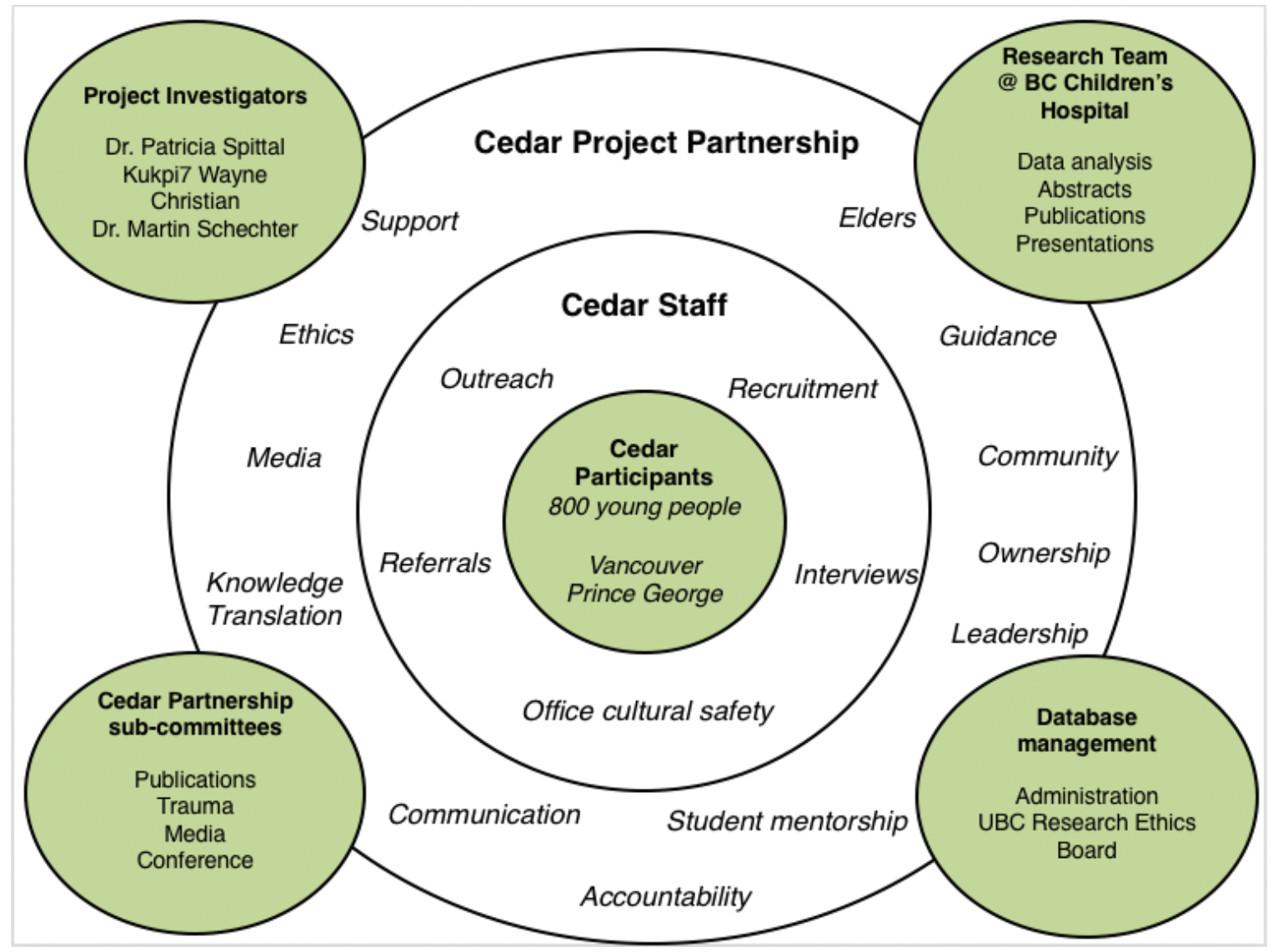

Figure 2: Cedar Project Governance model. Image reproduced with permission of Cedar Project Partnership. 
The Partnership determines the research priorities, defines research questions, and identifies critical areas of analysis. Partners review study protocols, provide guidance on design, and assure ethical standards are met. They determine the interpretation of results and develop recommendations rooted in the belief that connection to culture, ceremonies, traditions, and languages is critical to Indigenous people's healing and wellness journeys. All efforts are made to incorporate and address local concerns, wisdom, and recommendations at each step of the project. Throughout, the researchers participate in community meetings to discuss the results of the analysis with the Cedar Project Partnership members. Partners are identified as co-authors on all Cedar publications and often co-present at conferences. Importantly, the Partnership controls all communication and media strategies (Figure 3). Decisions are based on consensus and Indigenous voices are privileged.

As Dr. Patricia Spittal, principal investigator of Cedar, has described the role of Cedar governance:

We get a directive. It's governance, and I do what they say. They are our oversight. Indigenous voice is privileged-that's really important. Non-Indigenous voices don't get the final say. Our Elders have mentored me. When I screw up, I am held accountable, and I am mentored through it. This has been critically important because we work within such systemically racist environments in university and healthcare. I am still learning, and I am still being mentored by them. (Patricia Spittal, personal communication to Richa Sharma, January 30, 2019)

An example of how Cedar governance directs process is when Dr. Spittal was tasked to approach the Vancouver Police Department and RCMP to discuss contentious Cedar findings highlighting sexual assault by police officers prior to the release of the study (Pan et al. 2013).

Built within this organizational infrastructure are four key features largely responsible for ensuring a successful governance model: inclusion of Elders; cultural safety; knowledge translation (including community dissemination, media relations, and evidence-based advocacy); and the student mentorship program.

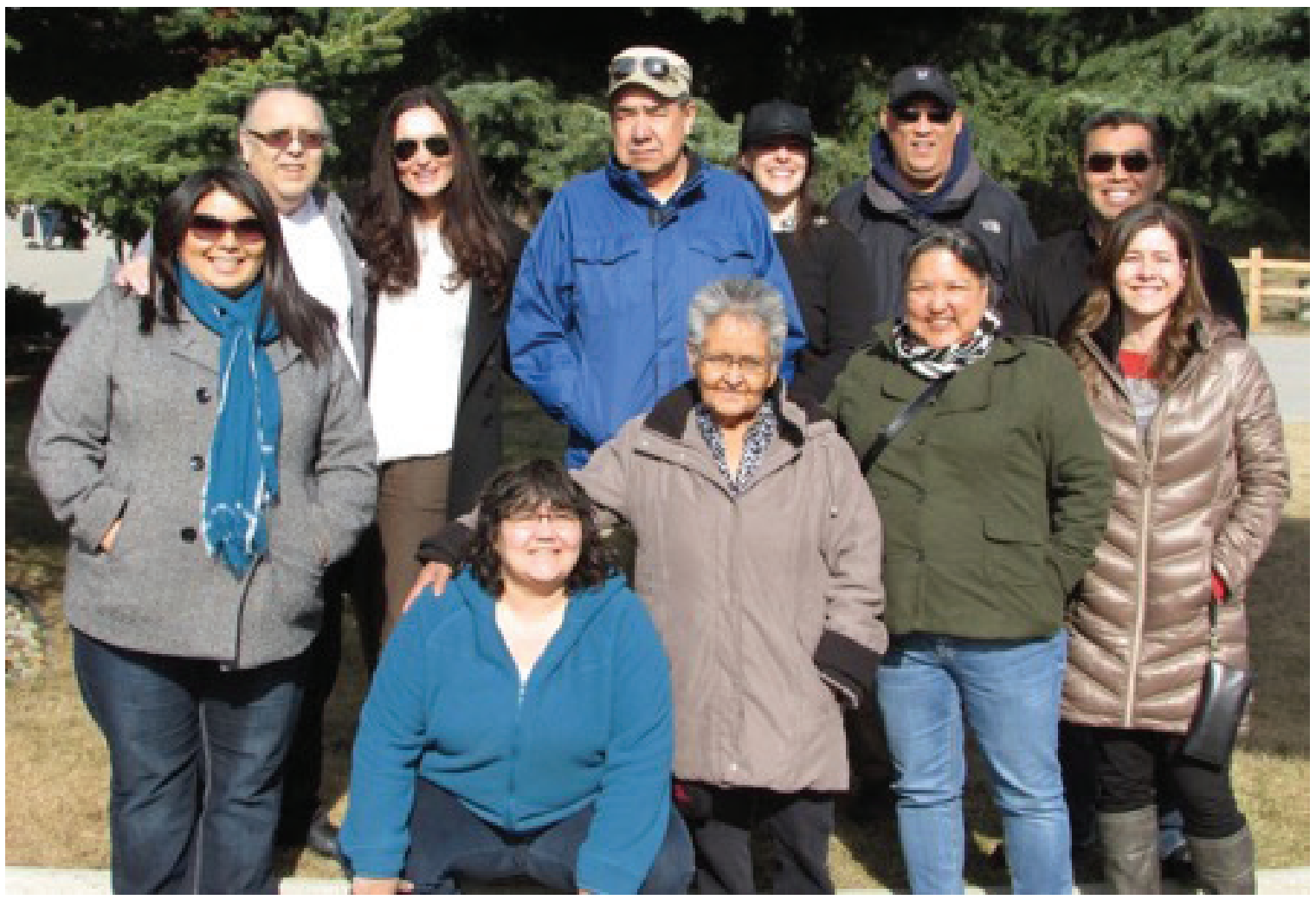

Figure 3: Cedar Project Partnership (from top left to bottom right): Elder Earl Henderson, Patricia Spittal (UBC), Elder Lou Demerais, Kate Jongbloed (UBC), Sandy Lambert (Red Road), Preston Guno (CSFS), Marilyn Janzen (CSFS), Vicky Thomas, Elder Violet Bozoki, Sherri Pooyak (CAAN), Janet Gardiner (CIHNS). Photo reproduced with permission of Cedar Project Partnership. 


\section{The Elders}

Elders have taught us that research in Indigenous communities must be grounded in Indigenous worldview, ways of life, and ceremony. Doing research "in a good way" means that research is conducted respectfully and benefits the community as a whole. There is an understanding that research relationships take time and there is an accountability to the greater Indigenous community about the research that is undertaken (AHA Centre 2018).

A key foundation of this relationship is the recognition that culture and traditions are passed on by Cedar Project Elders and knowledge keepers Earl Henderson (Cree, Métis), Violet Bozoki (Lheidli T'enneh), and Lou Demerais (Cree, Métis). They guide us in being accountable to participants by prioritizing their safety and well-being, asking good questions, honouring their voices, and effecting change. They share their teachings on reciprocity with the research staff and other partners as guidance for how to work with Indigenous peoples. Elder Earl Henderson (Cree, Métis), adjunct professor at UNBC, reflects that Cedar's strength is in the relationships between the participants, partners, Elders, staff, students, and academics:

My take on why Cedar has been able to continue for so long is that it's running culturally and traditionally. If there is an issue around a certain protocol, how to culturally handle something, then Violet or I provide a teaching, and help to sort it out. Cedar is committed to that process. Part of this is that we as Elders need to walk our talk. We have to lead by example, or else the youth we are working with won't respect us.

Before any of the work happened, the staff established relationships with the participants. They got to know them. There's a perspective in academia that doing that introduces bias, but really, if you know the person, you know the right questions to ask. Without the trust, there would be no research. (Cedar Project Partnership 2018b)

Cedar has embraced the concept of relational accountability, with a methodology rooted in a community context and in demonstrating respect, reciprocity, and responsibility as ways to be accountable to Indigenous authority and oversight over the research process (Wilson 2008). This is how Cedar does research in a good way. We ensure that Elders are respected and heard and that their knowledge guides us in carrying out the research.

\section{Cultural Safety}

The Cedar Project Partnership shapes how the researchers and staff negotiate cultural safety in protecting participants. Cedar staff work hard to ensure that our research offices are culturally safe, welcoming spaces, where Indigenous identities are honoured and young people's voices are heard and respected. Cedar protocols for cultural safety are rooted in acknowledging the central role of spirit to Indigenous identity and the importance of connection to land and culture. The staff strive to earn the trust of the participants and to assure them that they will not be harmed or judged. Humility, understanding why people use drugs, and the role of substance use in supporting resilience of young Indigenous people help facilitate building long-lasting relationships between staff and participants. In addition, Cedar staff provide resource support for food security and housing.

Ensuring participant confidentiality is critical to maintaining relationships with participants rooted in trust. Given that Cedar Project participants often have stigmatized experiences involving homelessness, illicit substance use, sexual exploitation, and survival sex work, many have had traumatic experiences with the police and experienced systemic discrimination within the healthcare system (Pan et al. 2013; TurpelLafond 2020). In order to provide an added layer of protection for Cedar participants, our offices are policefree zones. Research staff are trained to ensure that if police arrive at our office doors, they are to be escorted off property, and the staff will talk with them on the streets where everybody can hear them. We also have an extensive consenting process with participants where the research staff inform them of their rights throughout the research process, including refusal to answer questions, and the circumstances around which confidentiality may be breached. This holds tremendous importance for the participants, as they are trusting the research staff with difficult stories and life experiences.

Cedar Project Coordinator Vicky Thomas (Wuikinuxv Nation) often talks about the difference between Western ethics and "NDN Ethics." The former strive to ensure the safety of participants in research, to ensure that work is done ethically and meets industry standards of care, and to ensure that no litigious action can be taken. In contrast, "NDN Ethics" strive to ensure not only the safety of the participants in research but also the accountability of the research to Indigenous communities, embodying relational accountability (Wilson 2008). As she describes, 
To make Cedar a culturally safe place for participants, I go on the teachings of my mom, my aunties, and other influential women in my life. You have to think of the office as a home, and think about what would you do to welcome someone into your home. We do things like have food, and it's ok for people to sleep away a shift on the couch, take a sponge bath in the bathroom, or make calls to family. (Cedar Project Partnership 2018b)

Embracing the epistemology of research as ceremony, the research is grounded in Indigenous worldviews and ways of life (Wilson 2008; Pooyak 2020). Cedar Project Elder Lou Demerais (Cree, Métis), founding Executive Director of Vancouver Native Health Society, explains the role of food and ceremony in the research process:

Food has always been central to everyone's cultures, no matter where they are. A meal automatically pulls people together. There's kind of an expectation that if you're feeding one another, you're doing good things for each other.

Ceremony is also important, including in research. There's a process of trying to reintroduce of what's been either lost, or perhaps temporarily forgotten, especially for those who might have been disconnected from their roots. In trying to fill the void that was left by the impacts of colonization, the idea, in my mind, is trying to get back as close as we can to our cultures, to some of the best parts, without overdoing it. What it boils down to is that our cultures represent the values of our folks. That underpins everything. (Cedar Project Partnership 2018b)

Honouring participants' voices is rooted in culture and ceremony and yearly gatherings with traditional foods, enabling us to maintain connections with participants over seventeen years. About three times per year, we offer traditional foods such as salmon or moose stew. Cedar partners often provide access to traditional foods, medicines (sage, cedar), gifts (blankets, bags), and ceremonies (feasts, memorials) for participants. We also hold yearly memorials with feast and ceremony to honour participants who have passed (Figure 4).

\section{Knowledge Translation}

Cedar governance recognizes that developing culturally safe interventions and knowledge translation materials that address the complexity of HIV and HCV vulnerability among young Indigenous people requires multidisciplinary contributions within an environment that supports safe, constructive, and meaningful dialogue. Extensive knowledge translation and community engagement is a hallmark of the Cedar Project Partnership.

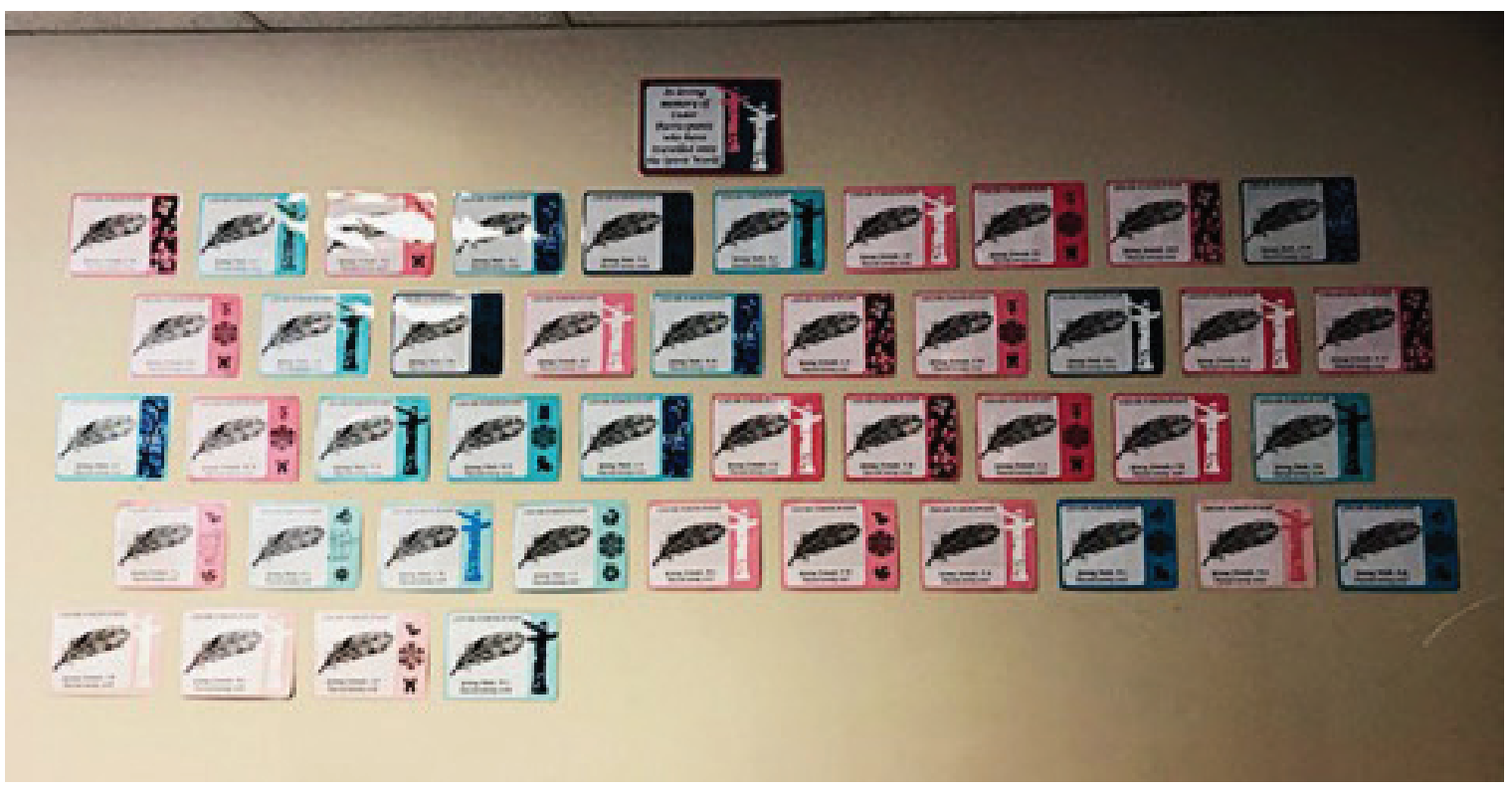

Figure 4: Honouring Cedar Project participants who have passed, Cedar Project Prince George office. Photo reproduced with permission of Cedar Project Partnership. 


\section{a. Community Dissemination}

Ceremony is an important part of Cedar's knowledge translation process. For example, in 2013 we received CIHR funding to hold a Learning Potlatch on Lheidli T'enneh territory (Figure 5). Elder Violet Bozoki (Lheidli T'enneh) guided us in the protocols of the Cedar potlatch because it was held on her territory. We hosted over two hundred attendees, including Cedar staff and partners, participants and their families, and community members. It was an opportunity for Cedar participants, many of whom have experienced family disconnections through child apprehension and having parents who attended residential school, to participate in culture and ceremony. We honoured our partners and participants with gifts, including blankets and dry goods. Through the potlatch, non-Indigenous Cedar researchers and staff witnessed the powerful impact of ceremony in the knowledge translation process. As Vicky Thomas (Wuikinuxv Nation) notes,

Our people don't end up on the street, don't end up in addiction, unless there's quite a bit of trauma in their background. Knowing that that was the bulk of the information we were going to be sharing, it was important to bring our sexual abuse findings back to our participants, their families, and their communities in a safe way. In a way that would honour them, that wouldn't place blame or shame, that celebrated their truth-and the best way to do that is through ceremony. (Cedar Project Partnership 2018b)

In addition, with support from CIHR Meetings, Planning and Dissemination Grants, we held a series of meetings to reflect upon what it means to have cultural safety when talking about HIV vulnerability; to disseminate Cedar results related to strengths-based culturally safe case management and mortality at the community level; to discuss barriers to harm reduction in rural and remote settings; and to facilitate communication between Elders and HIV-positive young people in Cedar about traditional sources of strength to support wellness. These meetings were held in ceremony, opened with a prayer and drumming led by an Elder, and included a meal with traditional foods.

\section{b. Media Relations}

Cedar governance is the face and voice of Cedar research. Cedar Project Partnership governs us through all knowledge translation, including print, TV, and radio press. The Partnership determines release of findings to the media, emphasizing community relevance, reciprocal responsibility, and privileging Indigenous

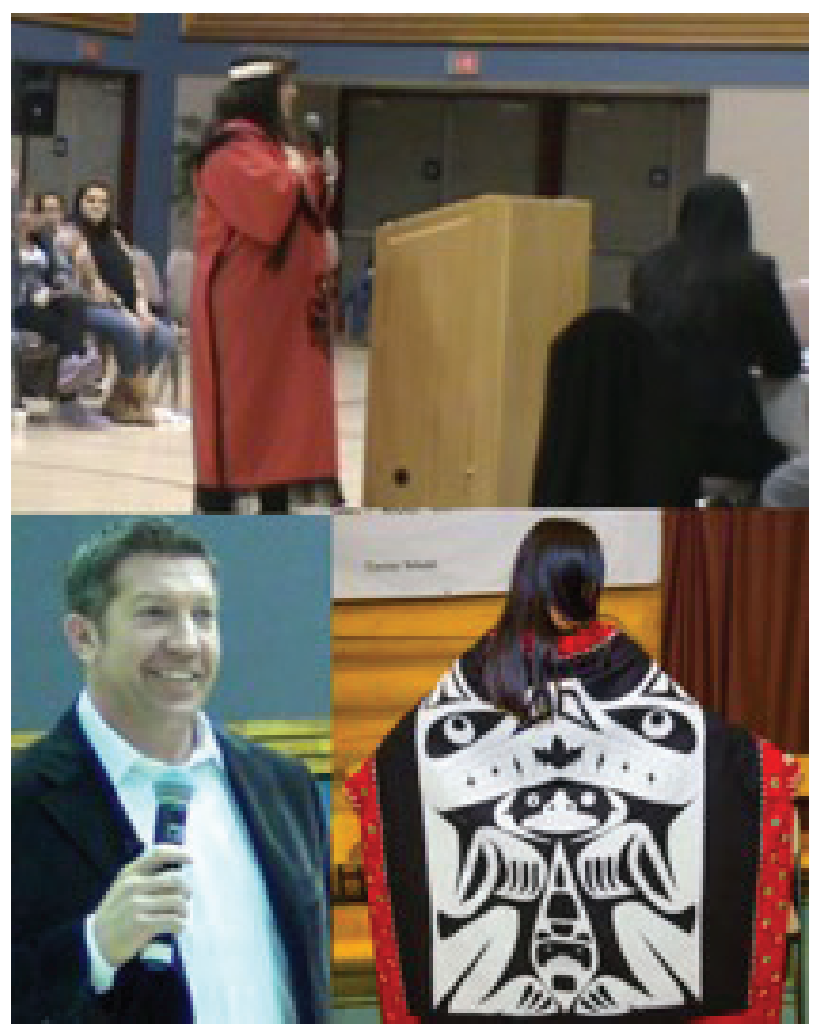

Figure 5: Cedar Project Potlatch, 2013. Photo reproduced with permission of Cedar Project Partnership. 
voices. It controls all communication and media strategies and determines how this research is presented to the communities and the public. It decides when the Project will go to the press, what the key messages will be, and who the spokespeople will be. The process involves 1) meeting to review findings/interpretation, make decisions regarding embargo/release, and agree on spokespeople; 2) working with UBC/BCCHRI communications on release; and 3) agreeing on messaging. Indigenous partners are always quoted and communications staff send any press to Indigenous partners first, who lead the dialogue on the meaning of the evidence. These practices and approaches are undertaken to ensure that difficult findings are released in a safe way, honouring the participants' voices and lived experiences.

For example, the governance met at least four times over a period of one year to get the results of our seminal 2008 paper (For the Cedar Project Partnership) appropriately interpreted and strategized for release to the press without blame, shame, and judgement. This process is not an exception; it is the norm. All our publications go through this journey. In 2017, we released a paper (Jongbloed et al.) demonstrating that young Indigenous people who use drugs in British Columbia are dying at an alarming rate, with concerning associations between death and HCV, suicide attempt, and recent non-fatal overdose. Chief Wayne Christian (Splats'in te Secwepemc) and Mary Teegee (Gitk'san and Carrier, Takla Lake) were interviewed for national radio and print/online press to discuss these difficult results (Bains 2017; Bellrichard 2017).

\section{c. Evidence-Based Advocacy}

Over the past seventeen years, Cedar has provided a critical evidence base to lead dialogue related to crises of sexual abuse, child apprehension, and HIV and HCV in Indigenous communities. The Partnership has used this evidence to advocate for their young people. For example, findings that highlighted worrying HIV/HCV prevalence in the North (Spittal et al. 2007) prompted a meeting with an unprecedented sixty of sixty-one Northern Chiefs, along with government representatives, and led to the establishment of the Northern Aboriginal HIV/AIDS Task Force and Prince George's first mobile harm reduction van.

Additionally, findings demonstrating the links between residential schools, childhood sexual abuse, and sexual assault (Pearce et al. 2015b) led to initial steps to create an Indigenous-led Child Advocacy Centre (CAC) in British Columbia, with Cedar providing scientific support. Cedar evidence was also presented to the RCMP, health directors, Chiefs/council, the Attorney General's office, and Northern Health Authority in 2013. In 2014, Cedar's coordinator and a participant presented the statistics at a meeting of First Nations leaders, emphasizing that intervention was urgently required. The next day, fifty-four Northern British Columbia Chiefs unanimously passed a resolution to support a CAC for young Indigenous people in British Columbia (Maki 2015). It will be the first in Canada.

\section{Student Mentorship Program}

The Cedar governance model includes mentoring Indigenous and non-Indigenous graduate students who work with the study to become ethical, culturally safe research scientists. Each student or trainee who works with Cedar is mentored closely by one of the Cedar Project Partnership members. This is part of our relational accountability (Wilson 2008). The Indigenous mentors provide oversight on each phase of study undertaken by the student, including ethics, data collection, interpretation, and reporting.

All graduate students receive training in the following core areas: Indigenous ways of knowing and doing; methodologies and research ethics and Tri-Council Policy Statement: Ethical Conduct for Research Involving Humans (TCPS), Chapter 9; relational accountability; community-based research methodologies (CBR); mixed-methods research and quantitative and qualitative data analysis; integrated knowledge translation; and responsible and accountable manuscript writing. Mentoring includes thinking "beyond the thesis," career trajectory planning, conflict resolution, global and Indigenous health diplomacy, and the importance of self-care in trauma-informed research. The student must also adhere to the Student Ethical Conduct: Agreement for Conducting Research with the Cedar Project. This mentorship model offers reciprocal responsibility: students receive one-on-one guidance from an Indigenous expert, assuring that they receive cultural wisdom and support while also ensuring that the student's contributions are meaningful for communities. As Elder Earl Henderson (Cree, Métis) states,

The other thing, too, is the relationship with the students. Violet and I mentor the students involved in Cedar to explain and help them understand what is culturally appropriate and why. Academics have to be humble and respectful-you can't go in there like you know everything. The participants are the experts, you're not. That's why you're there doing the research. (Cedar Project Partnership 2018b)

Cedar Project mentor Sherri Pooyak (Cree) has mentored several graduate students. She reflects on her experience as a mentor/Auntie to students: 
I think with mentoring students, it is more than just sharing what you know in an academic sense about methodologies or that kind of thing. It's more about supporting students to begin to get a sense of another worldview. It's about coming to understanding of what we mean when we talk about relationship ... an integrated worldview that includes how we understand the land, how we understand our environment, how we understand and interact with the spirits, how we interact with ceremony. I see my role as trying to help students learn about this so that when participants share their stories, I can give context and help interpret through this lens, and say, "You might want to frame it this way."

The other part of mentoring that I didn't expect is being a counsellor or confidant or Auntie-providing emotional support and guidance as students bear witness to very difficult stories related to participants' traumatic experiences. I don't think this is usually part of Western mentoring relationships. We care about the students, and so we want to see them be well, whether that's them sharing their struggles or successes. We have a role to help students through that. (Cedar Project Partnership 2018b)

Kate Jongbloed, a non-Indigenous student, received mentorship through this program during her doctoral dissertation. She shares that

As a student, I'm accountable to the Partnership through an Indigenous mentor. My mentors from the Partnership-Lou and Sherri, and the rest of the partners as well-are very patient and generous teachers, helping me to learn about and value Indigenous worldviews and ways of doing. These are things that I do not get a chance to learn in the classroom and sometimes it feels like I am doing two parallel degrees because there is so much to learn. These experiential learning opportunities are critical for me to participate meaningfully in this work as a non-Indigenous student researcher. (Pooyak and Demerais 2019)

This mentorship provides a special opportunity to build long-lasting relationships between students and mentors that move beyond the trainees' formal involvement with Cedar, a testament to the collective's commitment to anchoring research and the learning process in relationships.

\section{Research Ethics and Urban Indigenous Peoples}

The Cedar Project Partnership recognizes that we work within settler colonial institutions that impede selfdetermination and Indigenous authority in research. However, our governance model is designed to ensure that Indigenous leadership can assert control over the research process. Indigenous governance of this research study is upheld through a research agreement and routine relational accountability (Wilson 2008). We continuously strive and fight to ensure that Indigenous autonomy and authority are not compromised. As a collective, we are committed to upholding Indigenous self-determination and governance while navigating barriers within a settler colonial institutional structure.

The research agreement between the Cedar research team and the Cedar Project Partnership is meant to ensure accountability and transparency at all levels in the research process. While our governance model predates Chapter 9 of the Tri-Council Policy Statement: Ethical Conduct for Research Involving Humans (Research Involving the First Nations, Inuit and Métis Peoples of Canada), we have embraced their guidelines and incorporated them in our community-based research process (Government of Canada 2018). However, TCPS does not speak to ethical research practices involving Urban and non-Status Indigenous peoples. Given that Cedar participants come from diverse Indigenous communities, the Partnership upholds self-determination and decolonization practices by offering a research ethics framework acknowledging Urban Indigenous peoples' lived reality. This approach aligns with the premise that TCPS is meant to serve as a model for ethical conduct in research involving Indigenous peoples-it is not meant to replace ethical guidance offered by Indigenous peoples themselves. Instead, it is a tool to ensure that research involving Indigenous peoples is built on respectful relationships (Government of Canada 2018).

Specifically, our governance ensures the following: that we incorporate an understanding of Indigenous ways of knowing throughout the research process; that the communities involved have jurisdiction over the conduct of the research; that the partners provide leadership, support, collaboration, and partnership; that the Project ensures confidentiality; and that the Partnership has intellectual property and ownership of knowledge. The governance ensures that the research team upholds respect of the rights of biological samples-they are on loan to researchers. Since the beginning of the project, we have centered Indigenous self-determination, control, voice, and sovereignty. As demonstrated above, our ethics are governed by our Elders, who share their wisdom and guide us. 


\section{Conclusion}

In this paper, we shared how Indigenous governance in research is a powerful way to effect change in young Indigenous people's lives. Cedar's approach has made it possible for us to: 1) uphold Indigenous governance through seventeen years of committed relationships; 2) honour participants' voices through cultural safety; 3) integrate ceremony and Indigenous-led media relations in knowledge translation; 4) embark on intervention research rooted in Indigenous knowledges and values; 5) shift discourse towards strengths-based research affirming links between cultural connection and resilience; 6) provide a critical evidence base and lead dialogue related to crises of sexual abuse, the child welfare system, and HIV/HCV; and 7) shape learning opportunities in Indigenous health for Canadian health professionals and researchers in training. We hope that by sharing our approach with the larger research community we can contribute to doing research in a good way by centering Indigenous knowledges and privileging Indigenous voice.

\section{Acknowledgements}

We would like to acknowledge the traditional territories of the Coast Salish peoples, including the

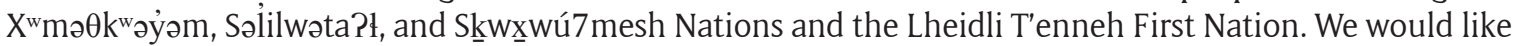
to acknowledge our Elders, Violet Bozoki (Lheidli T'enneh), Earl Henderson (Cree, Métis), and Lou Demerais (Cree, Métis), who have governed and guided our study from inception. We would also like to acknowledge our front-line staff, Vicky Thomas (Wuikinuxv Nation), Sharon Springer, Amanda Kupp (Ginoogaming Nation), Matthew Quenneville, Rachel Bergen, and Wesley Chu, who create safe spaces for our participants.

Finally, we would like to express our gratitude to the young people who continue to share their stories with us, and those who have passed away. We have lost more than ninety of the young people who have come in to visit us over the last seventeen years. They represent children, parents, husbands, wives, aunties, uncles, grandparents, and many other relations. We offer our condolences to their families and loved ones left behind.

"These deaths are not statistics; they are our relations." - Kukpi7 Wayne Christian, Secwepemc Nation, Co-Principal Investigator, the Cedar Project.

\section{References}

AHA Centre Fact Sheet. 2018. "AHA Centre: 'Doing Research in a Good Way."” Version 2. https://www.ahacentre.ca/uploads/9/6/4/2/96422574/research_in_a_good_way_finaljune_2018.pdf. Archived at: https://perma.cc/TRN2-93B7.

Bains, Camille. 2017. "Study Finds 'Appalling' Death Rate Among Young Indigenous Drug Users in B.C." The Globe and Mail, November 6, 2017. https://www.theglobeandmail.com/news/british-columbia/studyfinds-appalling-rate-of-death-among-young-indigenous-drug-users-in-bc/article36841253/\#: :tex$\mathrm{t}=0$-Study\%20finds\%20'appalling'\%20death\%20rate\%20among\%20young,Indigenous $\% 20 \mathrm{drug} \% 20$ users $\% 20$ in $\% 20$ B.C.\&text=Indigenous $\% 20$ drug\%20users $\% 20$ in $\% 20$ British,to $\% 20$ healing $\% 20$ deep\%2Drooted\%20pain. Archived at: https://perma.cc/YVE7-P86B.

Bellrichard, Chantelle. 2017. "Indigenous Youth Who Use Drugs in B.C. Dying at an Alarming Rate, Study Finds." CBC, November 6, 2017. https://www.cbc.ca/news/indigenous/indigenous-youth-drugs-d eath-1.4388450\#: :text=Indigenous-,Indigenous $\% 20$ youth $\% 20$ who\%20use $\% 20$ drugs $\% 20$ in $\% 20$ B.C.\%20dying\%20at\%20an,be\%20at\%20the\%20highest\%20risk. Archived at: https://perma.cc/ ATS6-U669.

Bill 41, Declaration on the Rights of Indigenous Peoples Act, 4th Sess, 41st Parl, British Columbia, 2019 (assented to 28 November 2019), SBC 2019, c 44. https://www.bclaws.gov.bc.ca/civix/document/id/ bills/billsprevious/4th41st:gov41-3. Archived at: https://perma.cc/YJ4R-CPAZ.

Capostinsky, Christal. 2007. In the North: From Corner to Corner: The Needs, Trends, and Working Conditions of Sex Workers in Prince George, British Columbia. Prince George, BC: New Hope Society. Canadian Electronic Library/desLibris. https://www.deslibris.ca/ID/216594.

Caron, Nadine, Patricia M. Spittal, Vicky Thomas, Wayne M. Christian, and Mary Teegee. 2016. "The Cedar Project." Session at the UBC Centennial Emerging Research Workshop on Ethics and Pragmatism in Indigenous Research, Vancouver, BC, February 22-24, 2016.

Cedar Project Partnership. 2018a. Partnership Meeting, December 13, 2018. Prince George, BC.

Cedar Project Partnership. 2018b. "The Cedar Project: Reflecting on Process." Indigenous Research Support Initiative. http://vpri-irsi.sites.olt.ubc.ca/2018/09/20/blog-4/\#: :text=Since\%202003\%2C\%20 the\%20Cedar\%20Project,use\%20drugs\%20in\%20British\%20Columbia. Archived at: https://perma.cc/ S2ZW-ZJA8.

Chandler, Michael J., and Christopher Lalonde. 1998. "Cultural Continuity as a Hedge Against Suicide in Canada's First Nations." Transcultural Psychiatry 35 (2): 191-219. https://doi.org/10.1177/136346159803500202. 
Christian, Kukpi7 (Chief) Wayne, for the Cedar Project Partnership. 2013. "The Legacy of Residential Schooling: Acknowledging the Pain of our Children." Presentation for the Canadian Academy of Health Sciences, Ottawa, ON, September 2013.

Christian, Wayne M., and Patricia M. Spittal. 2008. "The Cedar Project: Acknowledging the Pain of Our Children." The Lancet 372 (9644): 1132-33. https://doi.org/10.1016/S0140-6736(08)61460-9.

Craib, Kevin J. P., Patricia M. Spittal, Evan Wood, Nancy Laliberte, Robert S. Hogg, Kathy Li, Katherine Heath, Mark W. Tyndall, Michael V. O'Shaughnessy, and Martin T. Schechter. 2003. "Risk Factors for Elevated HIV Incidence Among Aboriginal Injection Drug Users in Vancouver." Canadian Medical Association Journal 168 (1): 19-24.

Craib, Kevin J. P., Patricia M. Spittal, Sheetal H. Patel, Wayne M. Christian, Akm Moniruzzaman, Margo E. Pearce, Lou Demerais, Christopher Sherlock, Martin T. Schechter, and Cedar Project Partnership. 2009. "Prevalence and Incidence of Hepatitis C Virus Infection Among Aboriginal Young People Who Use Drugs: Results from the Cedar Project." Open Medicine: A Peer-Reviewed, Independent, Open-Access Journal 3 (4): e220-e227.

First Nations Health Authority. 2014. Traditional Wellness Strategic Framework. Coast Salish Territory; West Vancouver, BC: First Nations Health Authority. https://www.fnha.ca/WellnessSite/WellnessDocuments/ FNHA_TraditionalWellnessStrategicFramework.pdf. Archived at: https://perma.cc/P8PZ-VUZ2.

For the Cedar Project Partnership, Adam F. Clarkson, Wayne M. Christian, Margo E. Pearce, Kate A. Jongbloed, Nadine R. Caron, Mary P. Teegee, Akm Moniruzzaman, Martin T. Schechter, and Patricia M. Spittal. 2015. "The Cedar Project: Negative Health Outcomes Associated with Involvement in the Child Welfare System Among Young Indigenous People Who Use Injection and Non-Injection Drugs in Two Canadian Cities." Canadian Journal of Public Health 106 (5): e265-e270. https://doi.org/10.17269/cjph.106.5026.

For the Cedar Project Partnership, Margo E. Pearce, Wayne M. Christian, Katharina Patterson, Kat Norris, Akm Moniruzzaman, Kevin J. P. Craib, Martin T. Schechter, and Patricia M. Spittal. 2008. "The Cedar Project: Historical Trauma, Sexual Abuse and HIV Risk Among Young Aboriginal People Who Use Injection and Non-Injection Drugs in Two Canadian Cities. Social Science \& Medicine 66 (11): 2185-94. https://doi. org/10.1016/j.socscimed.2008.03.034.

Fournier, Suzanne, and Ernie Crey. 1997. Stolen from Our Embrace: The Abduction of First Nations Children and the Restoration of Aboriginal Communities. Vancouver, BC: Douglas \& McIntyre.

Government of Canada. 2019. "TCPS 2 (2018) - Chapter 9: Research Involving the First Nations, Inuit and Métis Peoples of Canada." Panel on Research Ethics. Last modified September 23, 2019. https://ethics. gc.ca/eng/tcps2-eptc2_2018_chapter9-chapitre9.html.

Institute on Governance. 1997. Summary of the Final Report of the Royal Commission on Aboriginal Peoples. https://iog.ca/docs/1997_April_rcapsum.pdf. Archived at: https://perma.cc/H7YV-TRBB.

Jongbloed, Kate, Margo E. Pearce, Sherri Pooyak, David Zamar, Vicky Thomas, Lou Demerais, Wayne M. Christian, Earl Henderson, Richa Sharma, Alden H. Blair, Eric M. Yoshida, Martin T. Schechter, and Patricia M. Spittal, for the Cedar Project Partnership. 2017. "The Cedar Project: Mortality Among Young Indigenous People Who Use Drugs in British Columbia." CMAJ: Canadian Medical Association Journal 189 (44): E1352-E1359. https://doi.org/10.1503/cmaj.160778.

Kovach, Margaret. 2009. Indigenous Methodologies: Characteristics, Conversations, and Context. Toronto, ON: University of Toronto Press.

Maki, Allan. 2015. "Study Shows Link Between Continued Abuse of Aboriginal Women, Residential Schools." The GlobeandMail,April 10,2015. https://www.theglobeandmail.com/news/national/study-shows-link-between-continued-abuse-of-aboriginal-women-residential-schools/article23874393/\#: :text=Study\%20 shows $\% 20$ link $\% 20$ between $\% 20$ continued $\% 20$ abuse $\% 20$ of\%20aboriginal\%20women $\% 2$ C $\% 20$ residential\%20schools,-Open\%20this\%20photo\&text=Young\%20aboriginal\%20women\%20in\%20B.C.,a\%20 landmark\%20study\%20has\%20found. Archived at: https://perma.cc/9RAW-U74L.

Mehrabadi, Azar, Kevin J. P. Craib, Katharina Patterson, Warner Adam, Akm Moniruzzaman, Barbara WardBurkitt, Martin T. Schechter, and Patricia M. Spittal, For the Cedar Project Partnership. 2008. "The Cedar Project: A Comparison of HIV-related Vulnerabilities Amongst Young Aboriginal Women Surviving Drug Use and Sex Work in Two Canadian Cities." International Journal of Drug Policy 19 (2): 159-68. https:// doi.org/10.1016/j.drugpo.2007.07.005.

Moniruzzaman, Akm, Margo E. Pearce, Sheetal H. Patel, Negar Chavoshi, Mary Teegee, Warner Adam, Wayne Christian, Earl Henderson, Kevin J. P. Craib, Martin T. Schechter, and Patricia M. Spittal. 2009. "The Cedar Project: Correlates of Attempted Suicide Among Young Aboriginal People Who Use Injection and NonInjection Drugs in Two Canadian Cities." International Journal of Circumpolar Health 68 (3): 261-73. https://doi.org/10.3402/ijch.v68i3.18338.

Oppal, Wally T. 2012. Forsaken: The Report of the Missing Women Commission of Inquiry. Vancouver, BC: Missing Women Commission of Inquiry. Canadian Electronic Library/desLibris. 
Pan, Stephen. W., Chief Wayne M. Christian, Margo E. Pearce, Alden H. Blair, Kate Jongbloed, Hongbin Zhang, Mary Teegee, Vicky Thomas, Martin T. Schechter, Patricia M. Spittal. 2013. "The Cedar Project: Impacts of Policing Among Young Aboriginal People Who Use Injection and Non-Injection Drugs in British Columbia, Canada." International Journal of Drug Policy24(5):449-59. https://doi.org/10.1016/j.drugpo.2013.04.009.

Pearce, Margo E., Kate A. Jongbloed, Chris G. Richardson, Earl W. Henderson, Sherri D. Pooyak, Eugenia Oviedo-Joekes, Wunuxtsin M. Christian, Martin T. Schechter, Patricia M. Spittal, For the Cedar Project Partnership. 2015a. "The Cedar Project: Resilience in the Face of HIV Vulnerability within a Cohort Study Involving Young Indigenous People Who Use Drugs in Three Canadian Cities." BMC Public Health 15 (1): 1095. https://doi.org/10.1186/s12889-015-2417-7.

Pearce, Margo E., Alden H. Blair, Mary Teegee, Stephen W. Pan, Vicky Thomas, Hongbin Zhang, Martin T. Schechter, Patricia M. Spittal. 2015b. "The Cedar Project: Historical Trauma and Vulnerability to Sexual Assault Among Young Aboriginal Women Who Use Illicit Drugs in Two Canadian Cities." Violence Against Women 21 (3): 313-29. https://doi.org/10.1177/1077801214568356.

Pooyak, Sherri, and Lou Demerais. 2019. "The Cedar Project: Conducting Health Research in a Good Way." Presentation for Centre for Excellence in Indigenous Health, University of British Columbia, Vancouver, BC, February 18, 2019.

Pooyak, Sherri. 2020. "Ethical Research in Public Health Involving Aboriginal People in Canada." Guest presentation, DL 536: Aboriginal Public Health in Canada, School of Population and Public Health, University of British Columbia, Vancouver, BC. February 16, 2020.

Smith, Linda Tuhiwai. 1999. Decolonizing Methodologies: Research and Indigenous Peoples. London: Zed Books; Dunedin: University of Otago Press.

Spittal, Patricia. M., Kevin J. P. Craib, Mary Teegee, Catherine Baylis, Wayne M. Christian, A. K. M. Moniruzzaman, Martin T. Schechter. 2007. "The Cedar Project: Prevalence and Correlates of HIV Infection Among Young Aboriginal People Who Use Drugs in Two Canadian Cities." International Journal of Circumpolar Health 66 (3): 227-40. https://doi.org/10.3402/ijch.v66i3.18259.

Spittal, Patricia. M., Margo E. Pearce, Negar Chavoshi, Wayne M. Christian, Akm Moniruzzaman, Mary Teegee, and Martin T. Schechter. 2012. "The Cedar Project: High Incidence of HCV Infections in a Longitudinal Study of Young Aboriginal People Who Use Drugs in Two Canadian Cities." BMC Public Health 12 (632). https://doi.org/10.1186/1471-2458-12-632.

Tousignant, Michel, and Nibisha Sioui. 2009. "Resilience and Aboriginal Communities in Crisis: Theory and Interventions." Journal of Aboriginal Health 5 (1): 43-61. https://jps.library.utoronto.ca/index.php/ijih/ article/download/28977/23907/.

Truth and Reconciliation Commission of Canada. 2015. Final Report of the Truth and Reconciliation Commission of Canada. Toronto, ON: James Lorimer \& Company. https://www.rcaanc-cirnac.gc.ca/eng/1 450124405592/1529106060525\#chp2. Archived at: https://perma.cc/PZL7-7U95.

Turpel-Lafond, Mary Ellen. 2020. In Plain Sight: Addressing Indigenous-specific Racism and Discrimination in B.C. Health Care. Addressing Racism Review, Summary Report, November 2020. https://engage.gov. bc.ca/app/uploads/sites/613/2020/11/In-Plain-Sight-Summary-Report.pdf. Archived at: https:// perma.cc/6RK9-YC74.

Walter, Karina L., and Jane M. Simoni. 2002. "Reconceptualizing Native Women's Health: An 'Indigenist' Stress-coping Model." American Journal of Public Health 92 (4): 520-24. https://doi.org/10.2105/ ajph.92.4.520.

Wilson, Shawn. 2008. Research Is Ceremony: Indigenous Research Methods. Black Point, NS: Fernwood Publishing.

How to cite this article: For the Cedar Project Partnership et al. 2021. Cedar Project: Conducting Health Research with Indigenous Peoples in a Good Way. KULA: Knowledge Creation, Dissemination, and Preservation Studies 5(1), https://doi.org/10.18357/kula.144

Submitted: 03 July 2020 Accepted: 19 March $2021 \quad$ Published: 22 June 2021

Copyright: @ 2021 The Author(s). This is an open-access article distributed under the terms of the Creative Commons Attribution 4.0 International License (CC-BY 4.0), which permits unrestricted use, distribution, and reproduction in any medium, provided the original author and source are credited. See http:// creativecommons.org/licenses/by/4.0/. 